\title{
An innovative model for business financing in wine production
}

\author{
Mina Angelova \\ University of Plovdiv Paisii Hilendarski \\ Bulgaria \\ mina.marinova@abv.bg \\ Daniela Pastarmadzhieva \\ University of Plovdiv Paisii Hilendarski \\ Bulgaria \\ daniela.pastarmadjieva@gmail.com \\ Penyo Georgiev \\ University of Plovdiv Paisii Hilendarski \\ Bulgaria \\ penyo@uni-plovdiv.bg
}

\section{Gergana Dimitrova}

University of Plovdiv Paisii Hilendarski

Bulgaria

gergana.gu@gmail.com

Abstract. Development of markets and market relations always leads to enhanced competition and increased consumer demand, thus making quality one of the key factor in success and survival of any organization. An important prerequisite for improving quality is also having an opportunity for flexible financing of organizations. The study focuses on small and medium-sized wine producers, located in Southern Wine Region in Bulgaria. The main purpose is to identify the challenges these producers are facing, related to ensuring financial funds. We base our conclusions on the data from various official sources including the European Commission and Bulgarian National Agencies as well as our own data. The latter has been collected through questionnaires, spread among local wine producers at the beginning of July 2017. The selected approach confirmed some of the conclusions made in the official sources concerning the challenges faced by SMEs. Regarding the methodology we have concluded that it is better to reduce the number of questions or combine some of them. We also intend to start personal communication with managers of the companies in question. Also, we believe that in-depth interviews will help us understand better the circumstances behind the specific answers provided in the survey.

\footnotetext{
Received:

June, 2018

1st Revision:

August, 2018

Accepted:

November, 2018

DOI:

$10.14254 / 2071$

$8330.2018 / 11-4 / 8$
} 
Keywords: Bulgaria, wine production, innovation, financing, intelligent assistants, elearning.

JEL Classification: O33, G2, A1

\section{INTRODUCTION}

The issues of competitiveness are permanently relevant to our reality, where processes of globalization, internationalization, development of information technologies, scientific and technological progress are intertwined. Changes taking place in the business environment are constant. Moreover, these changes are increasingly difficult to predict while time for forecasting them is only getting shorter. It is the dynamically changing macroeconomic environment, as well as the conditions of the ongoing economic crisis, that put businesses in the everyday need to „fight for survival“, to be flexible, to respond adequately to the newly created conditions and to constantly adapt to them. This, in turn, implies seeking new forms of competitive behavior strategically placed and helping not only to keep them on the market but also to ensure their sustainable development. Successful are those leaders, who implement good practices, offer innovative solutions, achieve innovations and thus deliver higher value to consumers. In the context of the abovementioned (and not only) the issue of boosting competitiveness through innovations is becoming not only apparent but also imperative for both businesses and also whole economies at the national and global levels.

According to Michael Porter (Porter, 1990), who is one of the leading researchers of the competitiveness issues, ,a nation cannot be competitive in everything” and puts the focus not over the national economy but over „concrete industries and industrial segments” that have already demonstrated the most advanced levels of productivity.

Development of markets and market relations leads to enhanced competition and increased consumer demand, thus making quality one of the key factors in the success and survival of all organizations. One of the most important prerequisites for improving quality would be having flexible financing of organizations (Angelova and Pastarmadzhieva, 2017). Therefore, the topic of the current work is significant not only from the research standpoint but also from the standpoint of organizational activities in manufacturing and services sector.

The purpose of this study is to identify the challenges the wine-producing SMEs are facing when ensuring financing for their business. On the other hand, through the pilot study, we aim to test the questionnaires we have created for data collection.

In this sense, the research tasks of this analysis are:

1) to analyse and systematize the opportunities for flexible crediting of SMEs by EU funds;

2) to make a pilot survey with representatives of SMEs;

3) to highlight the problem areas connected with the opportunities for flexible financing;

4) to identify problems and challenges related to the gathering of data.

The current pilot study is part of a larger project. The core idea of the whole project is to create a model of innovative information platform that will assist the SMEs of the traditional for Bulgaria wine industry to receive financing by EU funds. The development of such platform aims at providing a support in financing connected with adopting innovation and new technologies, purchasing new technics and modernization of the equipment, producing qualitative wines, popularization of the Bulgarian wine on the global markets, etc. All of the latter are lined in the National Strategy for Development of Viticulture and 
Wine Production in the Republic of Bulgaria 2005-2025 as factors providing competiveness of the separate enterprises and the industry as a whole (Council of Ministers of Republic of Bulgaria, 2005).

In our study we focus on the obstacles that hinder the utilization of financial funds and instruments, provided by the European Union.

The object of the research is small and medium-sized enterprises from the wine industry, positioned in the territorial unit of Plovdiv (according to the division of territorial units and wine regions in Bulgaria of the Executive Agency for Vine and Wine, EAVW).

Although we focus on financial funds and instruments, provided by EU, wine producers can also utilize other options. We should note that crowdfunding offers interesting opportunities in the wine sector. There many scientists who have investigated the process of crowdfunding. They provide some guidelines for entrepreneurs how to run a successful campaign. Crowdfunding can be loosely defined as the fundraising for a project or a venture by a group of individuals, instead of professional parties (e.g. banks), usually taking place online - without any intermediary or through dedicated platforms (Schwienbacher and Larralde, 2012). It represents a promising source of funding for many types of actors that do not find solutions suited to their financing needs, mainly valuable for small and medium enterprises (OECD, 2015). Crowdfunding is a subject of growing interest for both scholars and policy makers. Many studies in the literature have analyzed crowdfunding market, participants' motivations, benefits and drawbacks, mainly on the basis of real user-experiences on the most popular crowdfunding platforms i.e. M. M. Gierczak (2016), Guidici et al (2013), J. Hemer (2011) etc. The Crowdfunding reward model, mainly in the form of pre-selling, represents a great opportunity and is ideally suited for the wine sector since an overwhelming majority of producers is represented by small entrepreneurs that have difficulties in accessing other forms of financing, but also because of some products and consumers' specific features (Mariani et al, 2017). Angela Mariani et al. (2017) makes a case study research that explores the experience of the first wine-dedicated crowdfunding platform, namely Fundovino ${ }^{1}$.

\section{LITERATURE REVIEW}

\subsection{EU policy for wine industry}

European Union is the biggest wine producer worldwide holding the following shares: $45 \%$ of world wine-growing areas; $65 \%$ of world wine production; $57 \%$ of global consumption; $70 \%$ of exports in global terms. Among the factors that affected considerably the development of wine market is the introduction of the common market organization (CMO). ${ }^{2}$

The first years of the new millennium were marked by a crisis in the wine industry in the EU. (Smith, 2008). The numbers indicated that through these years there had been a decrease in the wine consumption across the EU (Gavrila, 2009). So in 2008 a wine reform was performed. The main purposes of this reform can be summarized as follows 3 :

- Improving the competitiveness of European wine producers.

- Optimization of market-management rules in order to be simpler, clearer and more effective.

- Tradition-oriented wine growing with focus on its role in wine areas.

\footnotetext{
${ }^{1}$ https://www.fundovino.com/en

2 https://ec.europa.eu/agriculture/wine_en

${ }^{3}$ https://ec.europa.eu/agriculture/wine/reforms_en
} 
The new European wine policy stressed on four priorities: “(1) specific support measures for national support programs and for the transfer of financial resources to rural development measures; (2) regulatory measures for financial and regulatory aspects, including new measures for the classification system for quality wines and labeling rules; (3) measures relation to trade with third countries; and (4) rules governing production potential" (Gaeta \& Corsinovi, 2014).

Each EU member state adopted a strategy concerning the wine production and provides specific measures to support its wine producers. The measures can be single payment scheme, promotion, restructuring and conversion, green harvesting, mutual funds, and harvest insurance, investments in enterprises, by-product distillation.

It seems that the measures had an effect because although the share of wine production from the New World increases, Europeans still predominantly prefer wine from member states and the EU remains "world's largest market as regards wine production and consumption, as well as the chief exporter and importer" (Lombardi et al, 2016).

\subsection{Bulgarian SMEs and wine industry}

In Bulgaria there is a specific law on small and medium-sized enterprises, which was adopted in 1999. It regulates the implementation of the state policy to encourage the creation and development of SMEs. The first steps for support of the latter in Bulgaria were taken at the end of 1998. Their purpose was to ease the access of SMEs to credit resources. Taken together these steps form the main directions of the national policy on funding. (Vasilev, 2007). In 2008 according to managers of Bulgarian SMEs the main external factor impeding innovation is the limited access to financial resources (Panteleeva, 2008). The latter persisted on being a challenge for the SMEs through the next years alongside with the shortage of labor force and the frequent change in regulations (Ahmedova, 2014)

As concerns the wine production Bulgaria has a rich long-term experience. It has a favorable geographic location and soil- climatic conditions, which outline the subsector as one of the main subsectors for the Bulgarian economy. At the 40th World Congress of Viticulture and Wine Production held in Sofia, between 29.05.17 - 02.06.17, Bulgaria was ranked 21st in the world, regarding wine production, and 23rd as for the area of vineyards (International Organization of Vine and Wine, 2017).

Currently, the most of the regions in Bulgaria are defined as "rural areas", where more than a half the Bulgarian population lives. This contributes viticulture to be the main activity for a significant part of the latter. This, in turn, leads to the development of tourism, wine production, trade, education, etc. (Borisov \& Radev, 2011).

Bulgarian wine production is characterized by a wide assortment of white and red wines (bottled and bulk) as well as those with protected trademarks that compete on the domestic and foreign markets. Legislative framework related to regulation of the sector is unified in line with the European one so that our products can compete with other EU countries. Funding opportunities are increasing, incl. funding from European funds, thus providing financial resources to maintain a competitive level and competitive development. However, still the access to these funds is difficult, which demands the creation of opportunities to facilitate access to the necessary information, and hence the implementation, management and accountability of the financing itself.

In the context of a decline in wine consumption and a highly competitive environment in which the wine industry operates, it is necessary to seek opportunities to develop SMEs competitive advantages, overcoming their weaknesses and developing their competitive potential through the development and approbation of innovations. 
The National Strategy for Development of Viticulture and Wine in the Republic of Bulgaria 20052025 has goals, which have the potential to create favorable environment for the creation of such opportunities. They are as follows:

- Building a modern structure of the sector and increasing its competitiveness through the implementation of technological (process), product, marketing, management, organizational and information innovations;

- Stimulating SMEs in the industry to focus on concrete improvements and approbation of innovative solutions;

- Information provision for financing opportunities for enterprises in the industry, incl. the implementation of EU-funded investments in activities leading to enhanced competitiveness and in-house and sectoral development;

- Increasing the human resources capacity in the sector.

A significant part of Bulgarian wine producers are also focusing on differentiation and diversification strategies, seeking ways to promote their business, expanding their markets and increasing their sales, and offering uniqueness to achieve and develop competitive advantages.

The territory of Bulgaria is divided into two basic regions for producing regional wines (National Assembly of the Republic of Bulgaria, 2005): the Danube Plain and the Thracian lowland. Bulgaria is divided into six regions under NUTS 2 -Northwestern, Northern Central, Northeastern, Southeastern, Southwestern and Southern Central. The leader in wine production is The Southeastern region and near $60 \%$ of the whole wine production is located there. The next one is the South-central region, situated in The Thracian lowland and producing $21 \%$ of the whole production.

According to the data of the 40th World congress of Viticulture and Wine, in 2016 Bulgaria realized 600 thousand hectoliters wine export and the main markets are Poland, Russia, Great Brittan and The republic of China. At the same time the import is barely 50 thousand hectoliters. It is given an account of enhancing the quality of the exported wine in accordance with previous periods when the export was generally of low and middle class wines (International Organization of Vine and Wine, 2017).

In the period 2006-2016 the number of vineyards in Bulgaria was reduced. Nevertheless, the wine production and the creation of wine cellars increased. This, in turn, is a prerequisite for successful development of wine tourism and wine routes in specific wine destinations (Slavova and Peycheva, 2018). But it should be noted that in long run the success of wine regions as tourist destinations depends on the regional policies that support sustainable land use and the production of high-quality wines, which can attract the visitors. (Goranova and Tsvetanova, 2018). Furthermore, there is an evidence that the landscape has a significant role in the development of successful wine tourism (Borisov, Radev \& Nikolov, 2014).

Nevertheless, the wine production sector in Bulgaria still has a number of weaknesses. Among them are the lack of national budget for promotion of the wine sector both on outside and inside markets; a high level of alcoholic drinks consummation; a lack of developed distribution system; a low culture level for wine consumption; a low number of export wine enterprises as a proof for the low level of distribution system (Council of Ministers of Republic of Bulgaria, 2005).

Successful and „working“ good practices on a national scale are (Council of Ministers of Republic of Bulgaria, 2005):

1) the trend of bio wines;

2) the successfully developing wine tourism in Bulgaria;

3) periodically organized wine forums;

4) wine tasting; 
5) realization of cross-border projects for cooperation and exchange of experience in the sphere of wine production;

6) tools for the internationalization of Bulgarian products and the entering of new markets.

There are prospects for the wine industry, as this is a subsector, significant and distinct for the Bulgarian economy on a global scale - a fact that has been proven over the years. It is not surprising that the executive director of the Executive Agency on Vine and Wine (EAVW) Krassimir Koev claims that "wine will become one of the symbols of Bulgaria."

There is a competitive potential in this industry, which, if properly identified and successfully developed, would enhance the competitiveness on international markets' level.

The number of problems in the development of the sector requires research efforts and inculcating concrete recommendations for their elimination. The research connected with the opportunities for flexible financing has the potential to create prerequisites for enhancing the competiveness and improving the future perspectives of the sector.

\subsection{EU opportunities for financial support for wine industry in Bulgaria}

The SME Initiative - Bulgaria.

In 2016 Bulgarian government started the SME initiative. It is financed by various sources European Investment Bank, the European Investment Fund, European Commission and the national government (through Operational Programme "SME Initiative"). It aims at supporting the debt finance for SMEs; to increase the investment activities, productivity and growth capacity of SMEs. Under this initiative the latter doesn't receive finances directly but by loans through intermediaries. Bulgarian banks which are intermediaries in the SME initiative are United Bulgarian Bank, Raiffeisenbank Bulgaria, UniCredit Bulbank, Procredit Bank and CIBANK.

Various debt products are available under the following initiatives: SME Initiative, EFSI-Investment Plan for Europe, InnovFin, COSME, Progress Microfinance, Risk Sharing Instrument (RSI), JEREMIE.

Operational program "Innovations and Competitiveness" 2014-2020.

SMEs in wine industry can benefit from this program because SMEs are its main target group. Under this program they can receive financial support in two main areas - technological development and innovation and entrepreneurship and capacity for growth of SMEs. Some of the specific measures that can be useful for wine producers are development of product and production innovations; establishment of new enterprises in areas, related to European and regional challenges; enhancing the effectiveness in resources utilization, etc.

Rural Development Program 2014-2020.

According to Bulgarian RDP, in the wine sector financial assistance will not be granted for investments eligible for support under the National Program for Support of the vine and wine sector. The RDP doesn't support certain variety changes, restructuring of the vineyards and the improvement of the vineyard management techniques. It also doesn't support activities related to investments for the production of wine products and general expenses related to them eligible for support under the National Program for Support of the vine and wine sector. (European Commission, 2015)

Wine producers can apply for all other activities which are eligible for financial support under RDP and are not covered by the National Program for support of the vine and wine sector.. In general such activities are investments in physical assets, development of farms and enterprises, organic farming. Each

\footnotetext{
${ }^{4}$ http://epicenter.bg/article/Krasimir-Koev--Vinoto-shte-stane-edna-ot-emblemite-na-Balgariya/119539/11/34
} 
of these three areas has specific measures, but the presentation of such detailed review is not focus of the current work.

\section{METHODOLOGY}

For the purposes of our project, we made a pilot research for two reasons. On one hand, these results can provide an indicative data (see for example Teijnlingen and Hundley, 2001) and help us to make refinements in the questionnaires in order to receive detailed information in the full-scale survey. On the other hand, thus we tested the research process, including the survey approach, its distribution and data collection.

Scholars from the Faculty of Economics and Social Sciences, University of Plovdiv Paisii Hilendarski, situated in Plovdiv, Bulgaria conducted the pilot study. The scholars who conducted it are the authors of the current paper who worked together on the creation of the questionnaire, its distribution, data collection and data processing and analysis.

We base our conclusions on data from various official sources including European Commission and Bulgarian National Agencies as well as our own data.

The first step of our empirical research was a collection of information about SMEs in wine industry located in Southern Wine Region in Bulgaria. We used various sources of information to collect contacts of the wine producers, including official web sites. The latter include The National Vine and Wine Chamber (NVWC) ${ }^{5}$, Bulgarian business register ${ }^{6}$ and Register of Cooperatives in Bulgaria ${ }^{7}$. Then the research team spread the questionnaires among the wine producers at the beginning of July 2017 and collected the replies by the end of November 2017.

For the purposes of the pilot study, we sent the survey to the official e-mail addresses of all the wine producers, i.e. 226 companies from Plovdiv area. The survey was developed on LimeSurvey and a link of it was attached to the letters. The letters also had a text, which described the survey and its purposes, the purposes of the project and the team of the project.

The survey itself has three parts: 1) General information, 2) Enterprise information, 3) Information regarding the financial instruments used by the enterprise.

The first part "General information" consists of three questions - gender of the respondent, age group (up to 25 years; $26-36$ years; $37-46$ years; $47-56$ years; over 56 years) and years of service (up to 1 year; $1-5$ years; $6-10$ years; $11-15$ years; $16-20$ years; over 20 years)

The second part of the survey is titled "Enterprise information". It requires the respondents to provide information about the following:

1) Total number of the people working in the enterprise (up to 50 people; $50-250$ people; over 250 people);

2) The markets covered by the enterprise (Bulgarian; European; World);

3) Form of ownership (state property; mixed, with predominantly state involvement; mixed, with predominantly private involvement; private property);

4) Type of the location where the production is located (big city-regional center; small town; village);

5) For how long the enterprise exists (up to 1 year; $1-5$ years; 6-10 years; $11-15$ years; $16-20$ years; over 20 years);

\footnotetext{
${ }^{5}$ http://bulgarianwines.org/

${ }^{6}$ http://www.brra.bg/

${ }^{7}$ https:// registarnakooperatsiite.com/
} 
6) Origin of the raw material used (respondents are asked to write down the area of their own vines in decar and/or the weight of grapes from suppliers in tons);

7) Their production (there is a list from which they may select as much answers as they want among the following: red wines, white wines, rose, bio wine, sparkling wines, vinegar, others).

The third part of the questionnaire is the most essential one. It consists of seven questions. In the first question, the respondents are asked about the sources of their financing. They may select as much answers as they want among the following: Using resources of the owner, his family and friends; Financing by EU programs; Bank loans; Credit line; Financing by government programs; Bank guarantees; Overdraft; Financing by international programs, outside the EU; Other.

The respondents are invited to point out the sources that they use to gather information about the options to receive financing. The list includes: official web sites of EU, the central and local authorities and state agencies; Executive Agency for Vine and Wine; personal contacts; the media; web sites offering services for making projects; web sites of NGOs; information panel of the territorial Agency for Vine and Wine - Plovdiv; their bank advisor.

In the next question, the respondents are asked to indicate the level to which they agree or disagree with some statements. The scale is from 1 to 7 , as "1" indicates "Absolutely agree" and "7" - "Absolutely disagree". The statements are as follows:

- I am aware of INNOVFIN programme;

- I am aware of the opportunities for financing provided by Horizon 2020;

- I am aware of COSME Programme;

- I am aware of the opportunities for financing provided by Operational Programme "Human resources development" 2014-2020;

- I am aware of the opportunities for financing provided by The SME Initiative Bulgaria (2014-2020);

- I am aware of the opportunities for financing provided by Operational Programme "Innovation and competitiveness" 2014-2020;

- I am aware of the opportunities for financing provided by Rural Development Programme 2014-2020.

The fourth question of this part is an open one and the respondents are asked to write down the web address of an online platform, which helped them in finding financing. The purpose of this question is to identify any platforms similar to the one that the research team plans to develop.

The next question is related to the challenges, which SMEs face. The respondents are asked to indicate the level to which a certain obstacle is a challenge for them. The scale is from 1 to 7 , as " 1 " indicates "Absolutely not a challenge" and "7" - "Very serious challenge". The options are as follows: Finding qualified employees; Regulations; Finding qualified managers; Finding clients; The production costs; The labor costs; The competition; Access to financing.

The sixth question in this part also uses a scale from 1 to 7 and the respondents are asked to indicate to what level each of the statements is valid for them. "1" indicates "Absolutely not valid for me" and "7" - "Absolutely valid for me". The statements are as follows:

- I received financing by EU program;

- I think that by EU programs only people with "friends in high places" are favored;

- The procedure of receiving EU financing was clear and impartial;

- I think that the EU funding is not meant for the people who really do business;

- I know that there is a high corruption level in EU funding procedures;

- I think that I have no chance to get EU financing and I will not apply for financing; 
- I received assistance by the administration concerning my project.

The last question aims at finding out whether the wine producers use ICTs and which ones, precisely. The list that we made for the pilot survey consists of some basic ICT equipment, regarding hardware, software and network. The respondents have a list of this equipment and have to choose between "Yes" or "No", as "Yes" means that they use it and "No" that they do not. The list includes: Computer; Printer; Scanner; Copy machine; Mobile phones; Tablet; Accountant software; Internet; E-mail; Text software (Microsoft Word, Pages, etc.); Electronic tables software (Microsoft Excel, Numbers, etc.); Specialized software for the wine industry; Cloud services; Specialized management software.

As this is a pilot study for the purposes of the current paper, we only made frequencies using the statistical software IBM SPSS Statistics 22. In addition, because this is a pilot study our experience with the selected approach is discussed in the conclusion of the current work.

\section{EMPIRICAL RESULTS AND DISCUSSION}

The study in the field of financing gives us an opportunity to identify the place of the latter among the problems faced by the Bulgarian wine producers. The figures below briefly represent the results from the empirical survey. We should note that the crowdfunding, mentioned above, is not part of the focus of the current paper and respectively of the empirical study. Its popularity among Bulgarian wine producers is going to be studied at a later stage. According to Survey on the Access to Finance of Enterprises, conducted by European Commission and the European Central Bank in 2016 access to finance is a challenge for 8,7\% of SMEs at EU level and for 9,8\% of companies in Bulgaria. In our survey, we asked the respondents to evaluate the significance of various challenges for their business. About $50 \%$ of them point ,access to finance“ as a very significant challenge (Figure 1). Although it is not the biggest challenge for them, it is one of high importance.

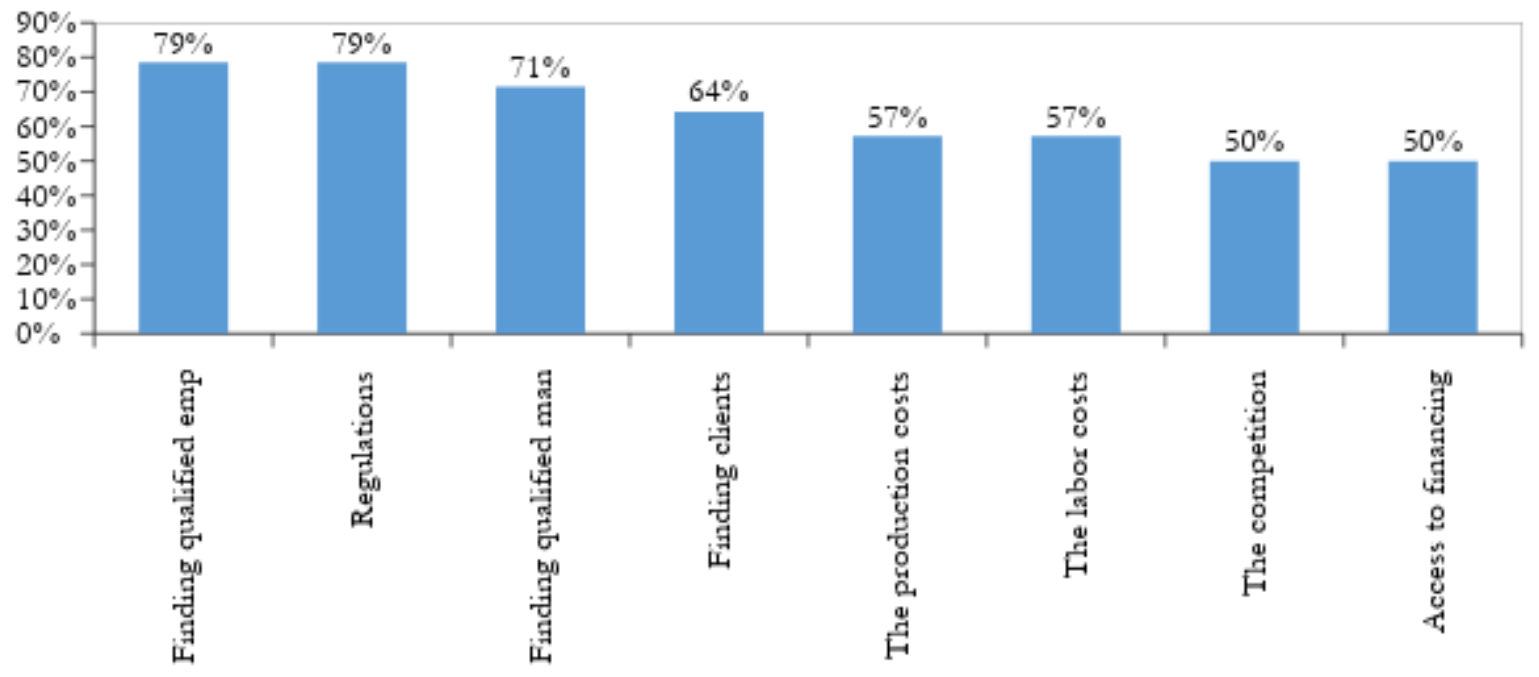

Figure 1. Basic challenges for SMEs in the wine industry Source: Own data.

One of the things that we wanted to find out is whether the wine producers are informed about the various opportunities provided by the EU for financing. The results displayed on Figure 2 show that most of the respondents are aware of the options. This result indicates a very positive trend. But the information about the existence of the certain program is not enough to lead to its utilization. 


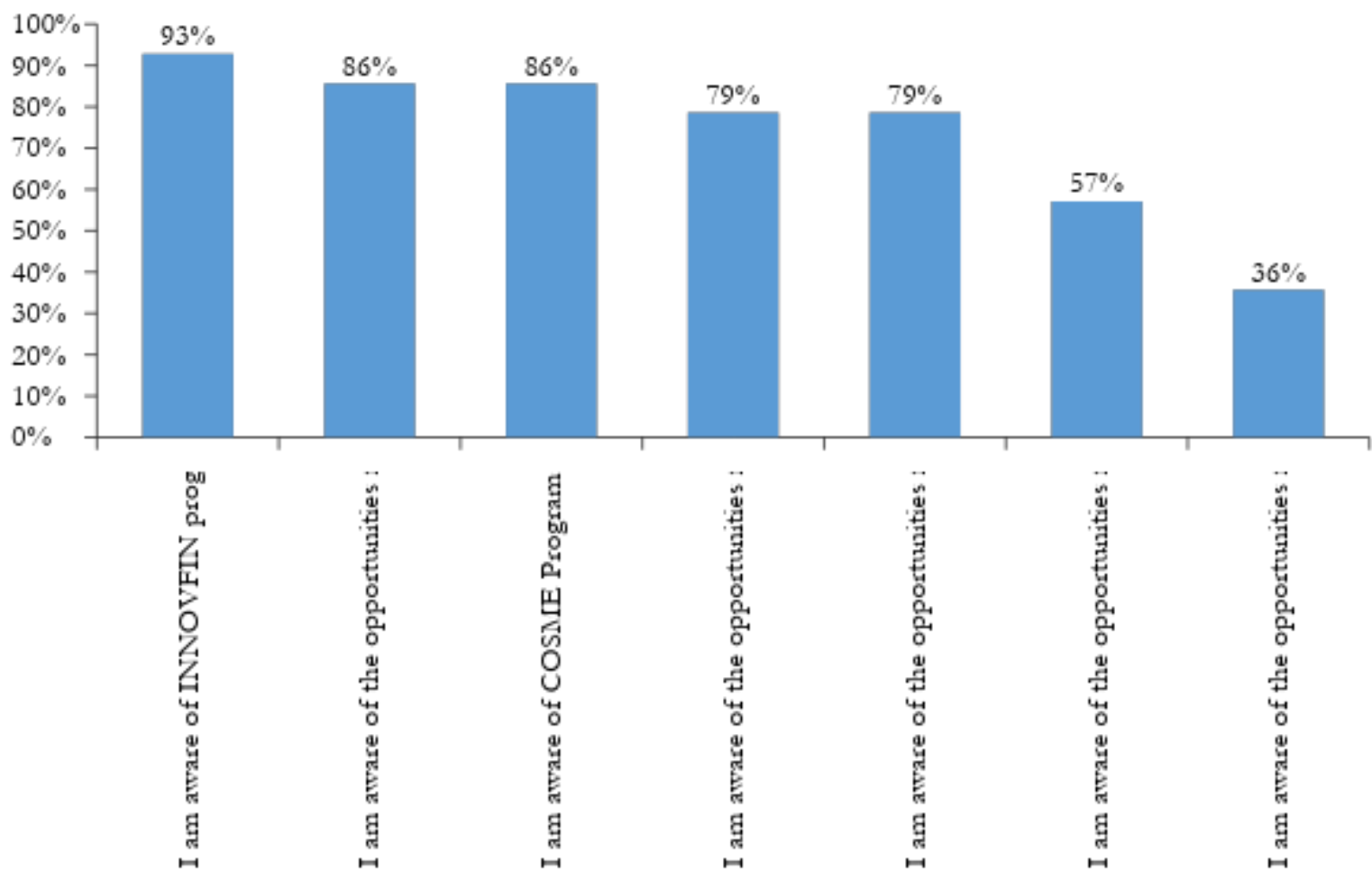

Figure 2. Information level

Source: Own data.

According to a survey published in an annual report from 2012 (more recent data isn't available) on the management of EU funds in Bulgaria about $56 \%$ of Bulgarians declare that they are fully or partially informed about the possibilities of EU funding. (National Assembly of Republic of Bulgaria, 2012) According to information of the representation of European Commission in Bulgaria from February 2017, the EIF provides a guarantee line of EUR 20 million, with which the NGF will support EUR 40 million in funding for SMEs in Bulgaria experiencing difficulties in securing the required collateral. The expectations are that 330 Bulgarian companies will benefit from the agreement in the next three years. ${ }^{8}$ But a research made by the Bulgarian economic journal „Capital“ by 9 July 2017 CIBANK and Raiffeisen bank both made almost 1400 contracts for about 150 million Euro. ${ }^{9}$ Very successful is also the new programming period for Operational Programme „Innovation and competitiveness“ 2014-2020.10 This indicates that our results correspond with the results from the official data.

A kind of confirmation is also the results about the sources of financing. Although most of the SMEs in wine industry rely on their own resources (43\%) about 30\% of the respondents also declare that they use financing through EU programs (Figure 3).

${ }^{8}$ https:/ / ec.europa.eu/bulgaria/news/40-miliona-evro-za-msp-v-Balgaria-po-investicionnia-plan-za-evropa_bg

9http://www.capital.bg/biznes/finansi/2017/07/09/3004019_sibank_otpuska_zaemi_za_oshte_200_mln_lv_po_programa/

${ }^{10}$ http://www.opcompetitiveness.bg/news.php?id=1228 


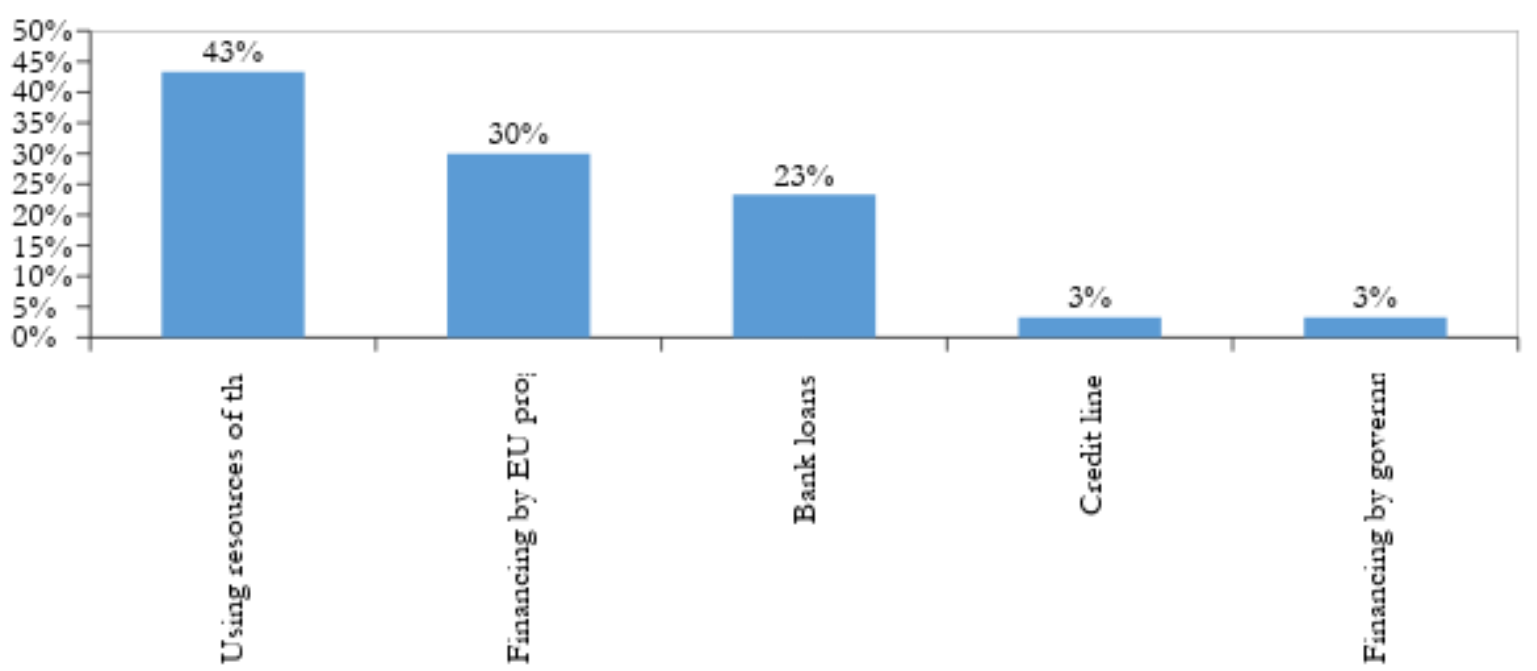

Figure 3. Ways of financing

Source: Own data

A very significant aspect relevant to the purposes of the current work is to find how wine producers receive information about the EU funding. One third (33\%) of them declare that the information comes from official web sites of EU, central and local authority and agencies. All these official sources are absolutely important but very often they offer a list of regulations. Also, frequently, people are not motivated enough to read all these regulations and give up on trying to find financial support from EU (Figure 4).

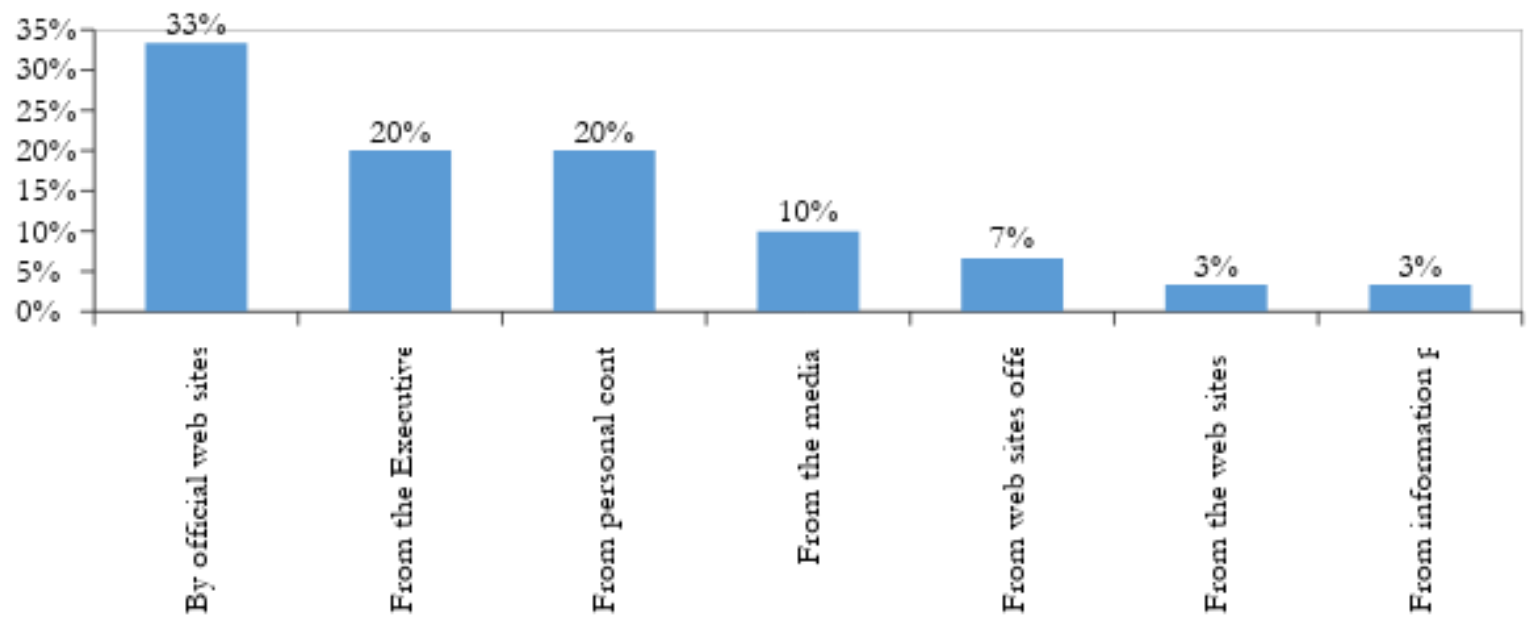

Figure 4. Information Sources

Source: Own data

Another deterrent factor may be some wide-spread beliefs, coming from journalists, analysts or politicians about the EU funding. Therefore, we wanted to test some of the beliefs of wine producers about the EU programs and their personal experience with them. The results in Figure 5 show that over $70 \%$ of the respondents have received financing from EU programs and $64 \%$ believe that the procedure was clear and impartial. Nevertheless, also 64\% share the opinion that people who have „friends in high 
places" mostly benefit from EU programs. And similarly, 50\% believe that the EU funding does not reach the people for whom it is intended. These results indicate some kind of incongruity because the results show that some of the people who received EU funding don't believe in the fair way of its distribution in Bulgaria.

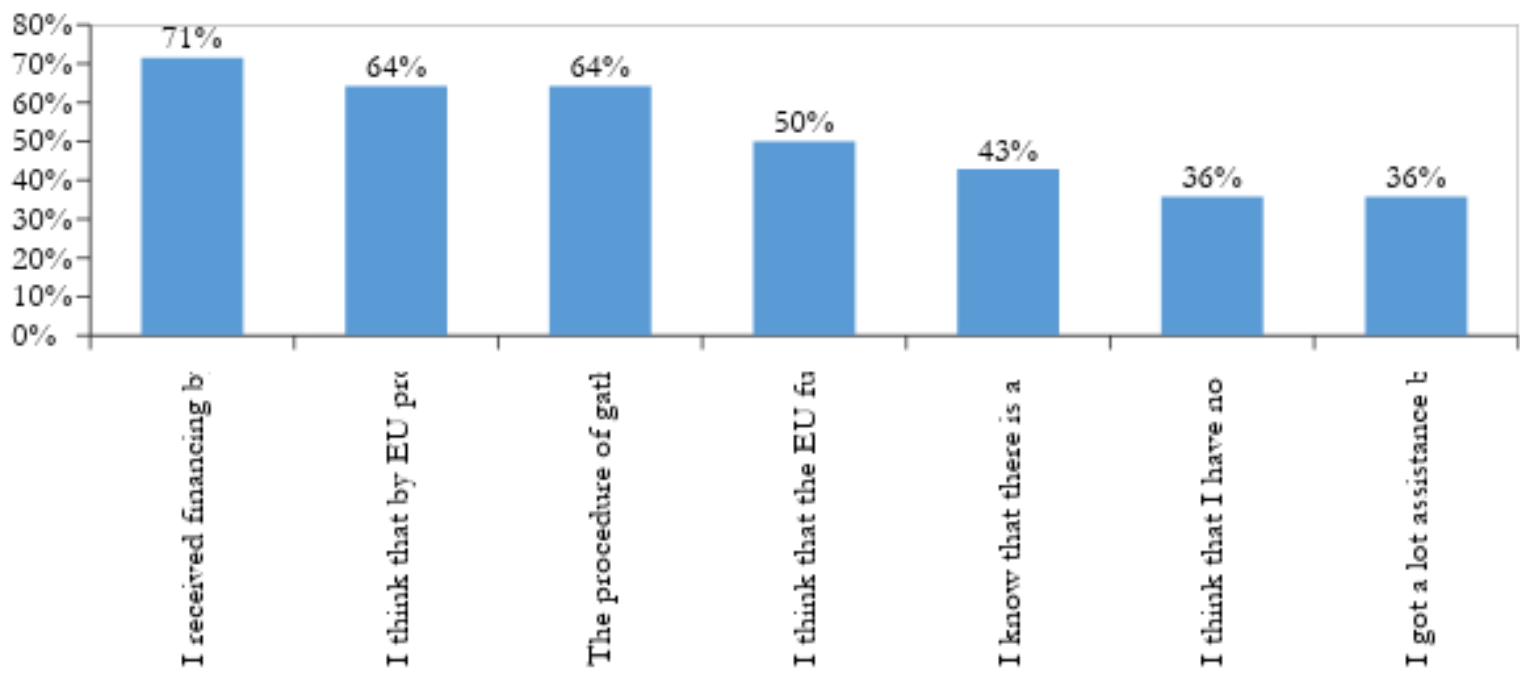

Figure 5. Opinions about the EU funding Source: Own data

As we try to develop an ICT instrument in favor of wine producers, we wanted to find what kind of ICT they utilize. The results in Figure 6 show that all of them use a computer, printer, scanner, copy machine, mobile phones, accounting software, internet, and e-mail.

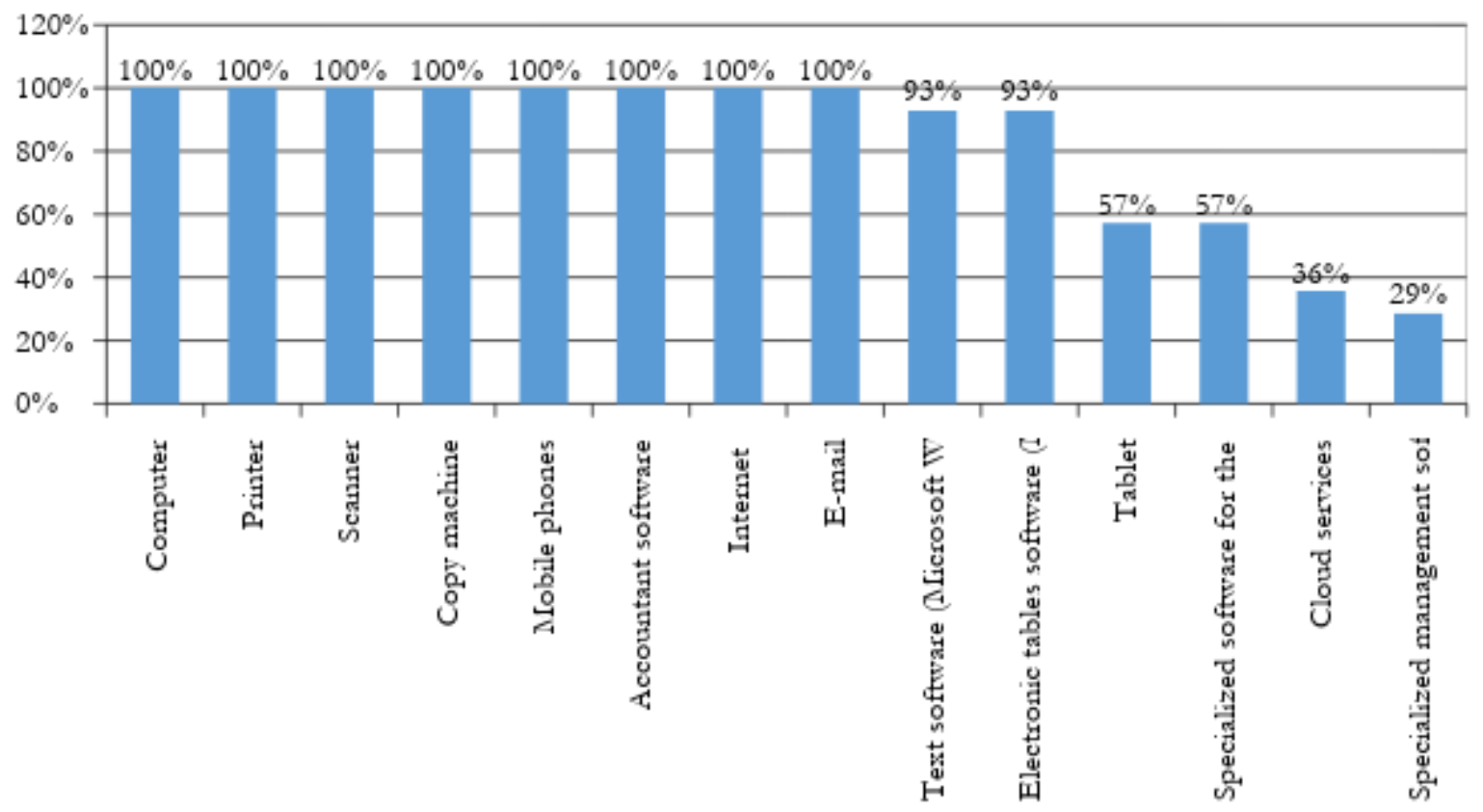

Figure 6. Used ICT

Source: Own data. 
Most of them also utilize text and electronic table software as well as tablets and specialized software for the wine industry. Just about $29 \%$ of them use specialized management software but the software we plan to develop is new for the market. They do not recognize a model or software that corresponds to our model of financing platform.

\section{CONCLUSIONS}

The research that we made on the studied topic and the pilot study lead us to the following conclusions.

As concerns the approach for data collection we identified some strong points and some challenges. The closed questions make the survey easier for the respondents and the collected quantitative data is easy to analyse statistically. But the latter may also become a weakness. In order to identify correlations between the variables, we needed more valid answers. Gathering more valid answers was a challenge in the current pilot study.

We also found that some of the respondents started to fill out the survey but then at some point stopped. This may mean that the questions were too much and the respondents didn't have the patience to fill them all.

In order to improve our methodology at the next stage, we plan to improve the questionnaire as we reduce the questions or combine some of them. We also intend to start personal communication with managers of the companies in order to convince them to participate in the survey. The e-mails in the current pilot study weren't personalized.

Furthermore we believe that in-depth interviews will help us to better understand the situation behind a specific answer from the survey. We intend to perform these interviews with some of the companies and not with all of them.

As concerns the results of the pilot study, some of them vary from the data of other scholars or institutions but others are close to already collected data. The latter is valid for the information level of wine producers and the EU funds and financial instruments utilization.

In our research, we focus on the access to finance as one of the key problems for the industry but not exclusively. In first place the respondents put the problem with finding qualified employees. Therefore, in our next study we intend to expand our focus on the human resources aspects.

\section{ACKNOWLEDGEMENT}

The article is published with the cooperation of Scientific research of the University of Plovdiv Paisii Hilendarski, project № PP18-FESS-008.

\section{REFERENCES}

Ahmedova, S. (2014) Importance of Small and Medium-Sized Enterprises (SMEs) for the Sustainable Economic Development of the North Eastern Planning Region. Yarbook ot Technical University of V arna, 1, 148-152.

Angelova, M. \& Pastarmadzhieva, D. (2017). Challenges and opportunities for flexible crediting of small and medium-sized enterprises in Bulgaria. Fundamental Sciences and Applications, 23, 167-170.

Borisov, P. \& Radev, T. (2011). Regional analysis of specialization of vine growing in Bulgaria. Agricultural economics and management, 56(2), 31-39.

Borisov, P. Radev, T. \& Nikolov, D. (2014). The Landscape as a Competitive Advantage for Wine Tourism Analysis of the competitiveness of the wine sector as an element of sustainable development.. Agricultural economics and management, 59(1), 28-37. Agricultural University - Plovdiv, Scientific Works, vol. LVII, Plovdiv.

Council of Ministers of Republic of Bulgaria (2005). National Strategy for Development of Viticulture and Wine Production in the Republic of Bulgaria 2005-2025. 
European Commission (2015). Bulgarian Rural Development Programme (RDP) 2014-2020.

European Commission (2017) Investment plan for Europe: $€ 40$ million for SMEs in Bulgaria, https://ec.europa.eu/bulgaria/news/40-miliona-evro-za-msp-v-Balgaria-po-investicionnia-plan-za-evropa_bg Retrieved November 25, 2017.

European Commission. The reforms of the EU wine market https://ec.europa.eu/agriculture/wine/reforms_en Retrieved July 20, 2017.

European Commission. Wine. https://ec.europa.eu/agriculture/wine_en Retrieved July 20, 2017.

Fundovino https://www.fundovino.com/en.

Giudici, G. Guerini, M. \& Rossi-Lamastra, C. (2013). Why crowdfunding projects can succeed: the role of proponents' individual and territorial social capital. SSRN Electronic Journal,. 1-20.

Gaeta, D. \& Corsinovi, P. (2014). Economics, Governance, and Politics in the Wine Market: European Union Developments. London: Palgrave Macmillan.

Gavrila, V. (2009). Particularities of the vine and wine market,. Agricultural Economics and Rural Development, VI(2), 277-291.

Gierczak, M.M. et al. (2016). Crowdfunding: outlining the New Era of Fundraising,. In D. Brüntje, \& O. Gajda (Eds.), Crowdfunding in Europe State of the Art in Theory and Practice (pp 7-23). Cham, Switzerand: Springer International Publishing AG.

Goranova, P. \& Tsvetanova, E. (2018). Research on the Importnace of Wine Tourism for the Sustainable Development of Regional Wine Production Areas in Bulgaria (Danube and Thracian). Scientific Research Almanac, 25(II), 167-197.

Hemer, J. (2011). A Snapshot on Crowdfunding, Karlsruhe: Fraunhofer.

Ilieva, V. (2017) Cibank provides loans for another BGN 200 million under the COSME program http://www.capital.bg/biznes/finansi/2017/07/09/3004019_sibank_otpuska_zaemi_za_oshte_200_mln_lv _po_programa/ Retrieved November 25, 2017.

International Organization of Vine and Wine (2017). 2017 World Vitiviniculture Situation, OIV Statistical Report on World Vitiviniculture.

Lombardi P. et al (2016). Development and trade competitiveness of the European wine sector: A gravity analysis of intra-EU flows. Wine Economics and Policy, 5(1), 50-59.

Mariani, A. Annunziata, A. Carmela, M. \& Nacchia, A.F. (2017). Crowdfunding and wine business: Some insights from Fundovino experience, Wine Economics and Policy, 6(1), 60-70.

Ministry of Economy (2017). Half a million leva per day reach the Bulgarian business thanks to the Operational Program "Innovation and Competitiveness". Retrieved November 28, 2017 from http://www.opcompetitiveness.bg/news.php?id=1228.

National Assembly of the Republic of Bulgaria (2005). State Gazette, vol. 67/16.08.2005

National Assembly of the Republic of Bulgaria (2012). Annual report on the management of EU funds in Bulgaria.

OECD (2015) New Approaches to SME and Entrepreneurship Financing: Broadening the Range of Instruments, Paris.

Panteleeva, I. (2008). The Innovations in SMEs in Bulgaria. In M. Petrov (ed) The Innovations: European, National and Regional Policies (pp 338-370), Sofia: ARC Fund.

Porter, M. E. (1990). The Competitive Advantage of Nations, New York: Free Press.

Schwienbacher, A. B. \& Larralde, B. (2012). Crowdfunding of Entrepreneurial Ventures. In D. Cumming (Ed.), The Oxford Handbook of Entrepreneurial Finance, (pp 359-391). Oxford: Oxford University Press.

Slavova, G. \& Peycheva, A. (2018). Sustainable Development of Wine Production in Bulgaria During the Period 2006-2016 Through Diversification Towards the Deevelopment of Wine Tourism. Paper presented at the a scientific conference „Regional Economics and Sustainable Development“ at the University of Economics, Varna

Smith, A. (2008). Globalization Within the European Wine Industry: Commercial Challenges but Producer Domination. In: B. Jullien \& A. Smith (Eds) Industries and Globalization. Globalization and Governance, (65-91). London: Palgrave Macmillan.

Teijlingen, E. R. \& Hundley, V. (2001). The importance of pilot studies, Social Research Update, 35.

Vasilev, Y. (2007). Financing and Lending of Small and Medium-sized Business in Bulgaria. Economic Bulletin of Donbas, 1, 162-170. 